\title{
Post-mortem 7.0-tesla magnetic resonance imaging of polymicrogyria
}

\section{Clinical image}

Polymicrogyria (PMG) is a malformation of cortical folding with disruption of the pialimitans associated with glial and macrophage accumulation. ${ }^{1}$ On magnetic resonance imaging of patients with PMG two patterns are observed: one with small fine, and undulating cortex with normal thickness and another with bumpy and abnormally thick cortex. $^{2}$ Also different types of hippocampus malformations can be associated to $\mathrm{PMG}^{3}{ }^{7}$-tesla MRI has main advances compared to those with 1.5 and 3 -tesla. ${ }^{4}$

We present a post-mortem 7.0-Tesla magnetic resonance imaging (MRI) study of a 70-year old man with a history of epilepsy, due to PMG and suspected hippocampal sclerosis. Six coronal sections of a cerebral hemisphere and a horizontal section of a cerebellar hemisphere were examined with $\mathrm{T} 2$ and $\mathrm{T} 2 *$ sequences. PMG was mainly observed in the parietal cortex. The hippocampus had a normal aspect. Moderate white matter changes (WMC) were present mainly in the parietal region. No cortical micro-infarcts were observed (Figure 1 ). On the $\mathrm{T} 2 *$ sequence only a few cortical micro-bleeds (CoMBs) were present. The cerebellar cortex had a normal appearance.

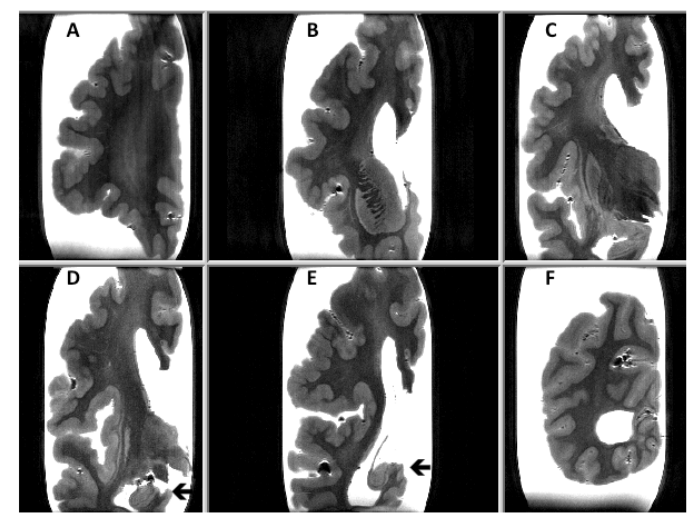

Figure I On the T2 MRI sequence polymicrogyria is mainly observed in the parietical cortex (sections D and F). The hippocampus has a normal appearance (arrows).

This is the first post-mortem study 7.0-tesla MRI study of PMG that confirms the validity of the "in vivo" imaging. The present case shows mainly parietal gyral malformations. The WMC and CoMBs are to be considered as age-related changes, as observed in normal
Volume 10 Issue 2 - 2020

\section{Jacques De Reuck}

Degenerative and Vascular Cognitive Disorders, Université de Lille 2, France

Correspondence: Jacques De Reuck, Degenerative and Vascular Cognitive Disorders, Université de Lille 2, INSERM UII7I, Lille, France, Email dereuck.j@gmail.com

Received: October 17, 2019 | Published: April 24, 2020

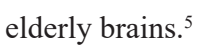

\section{Acknowledgments}

None.

\section{Conflicts of interest}

The author declares no conflict of interest.

\section{References}

1. Diamandis P, Chitayat D, Toi A, et al. The pathology of incipient polymicrogyria. Brain Dev. 2017;39(1):23-39.

2. Takanahi J, Barkovich AJ. The changing MR imaging appearance of polymicrogyria: a consequence of myelination. Am J Neuroradiol. 2003;24(5):788-793.

3. Kuchukhidze G, Koppelstaetter F, Unterberger I, et al. Hippocampal abnormalities in malformations of cortical development: MRI study. Neurology. 2010;74(20):1575-1582.

4. Guye M, Bartolomei F, Ranieva JP. Malformations of cortical development: The role of 7-Tesla magnetic resonance imaging in diagnosis. Rev Neurol. 2019;175(3):157-162.

5. De Reuck J, Auger F, Durieux N, et al. Cerebrovascular lesions during normal aging: a neuropathological study with 7.0-tesla magnetic resonance imaging. EC Neurology. 2018;10:229-235. 